\title{
360 Health Analysis (H360) - A Proposal for an Integrated Vision of Breast Cancer in Portugal
}

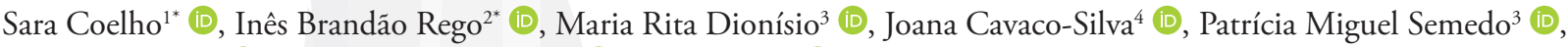 \\ Francisco Pavãos ${ }^{5}$ (D), Ricardo Baptista Leite ${ }^{6}$ (D), Luís Costa ${ }^{3,7}$ (D) \\ ${ }^{1}$ Instituto Português de Oncologia do Porto Francisco Gentil EPE, Porto, Portugal \\ ${ }^{2}$ Instituto Português de Oncologia de Coimbra Francisco Gentil EPE, Coimbra, Portugal \\ ${ }^{3}$ Hospital de Santa Maria, Centro Hospitalar Lisboa Norte, Lisbon, Portugal \\ ${ }^{4}$ ScienceCircle - Scientific and Biomedical Consulting, Lisbon, Portugal \\ ${ }^{5}$ Universidade Católica Portuguesa, Institute of Health Sciences, Lisbon, Portugal \\ ${ }^{6}$ Maastricht University, Faculty of Health, Medicine and Life Sciences, Maastricht, Netherlands \\ ${ }^{7}$ Instituto de Medicina Molecular, Faculdade de Medicina, Universidade de Lisboa, Luis Costa Lab, Lisbon, Portugal
}

\begin{abstract}
H360 aims to provide a comprehensive picture of breast cancer management in Portugal by retrieving real-world data from 10 Portuguese hospitals and deriving a snapshot from the medical interpretation of evidence-based data to patient perspective on the quality and effectiveness of medical care provided. This article reviews evidence on breast cancer clinical practice and quality of care and disease management in Portugal. A review of evidence on breast cancer clinical practice and quality of care over the last 10 years was performed in PubMed using the query "Organization and Administration"[Mesh] AND "breast cancer"[All Fields] NOT "Review" [ptyp]. National cancer initiatives relevant for quality of care and national and international guidelines and consensus were analyzed. Retrieved results showed that breast cancer incidence is still increasing, including in Portugal. Studies investigating disease outcomes seek to derive improvements to clinical practice and better financial resource allocation. Setting performance measures (KPIs) in institutions treating cancer is not a reality in Portugal yet, but has potential to leverage the quality of clinical performance. A multidisciplinary approach within one health structure is also desirable. More investment in clinical (including academic) research is key to optimize the quality of care. Implementation of clinical practice guidelines (largely based on ESMO guidelines in Portugal) is crucial to improve patient outcomes. Not less importantly, quality of life is a treatment goal on its own in breast cancer care. Breast cancer remains a health challenge and a multidimensional, 360-degree appraisal, beyond the exclusively clinical perspective, may provide new insights towards an optimal patient-centered approach.
\end{abstract}

Keywords: Breast cancer, Portugal, multidimensional, real-world, review

Cite this article as: Coelho S, Rego IB, Dionísio MR, Cavaco-Silva J, Semedo PM, Pavão F, et al. 360 Health Analysis (H360) - A Proposal for an Integrated Vision of Breast Cancer in Portugal. Eur J Breast Health 2020; 16(2): 91-98.

\section{Introduction}

Breast cancer is a highly prevalent disease associated with clinical, financial, and social burden worldwide. H360 Health Analysis is a multicentric pioneer project conducted in Portugal that aims to provide a comprehensive analysis of breast cancer management in Portugal. Collection of real-world data from 10 Portuguese hospitals and analysis of patients', health professionals', and hospital administrators' perspectives on the quality and effectiveness of breast cancer care provided is currently ongoing.

The present manuscript represents the first phase of this project and aims to provide a comprehensive review (a "360-degree" appraisal) of the state of the art regarding disease epidemiology, research, and management of breast cancer in Portugal, providing a framework for 'H360 Health Analysis' project.

\section{Methodology}

An electronic search on PubMed database was performed comprising the last 10 years using the query "Organization and Administration” [Mesh] AND "breast cancer"[All Fields] NOT "Review" [ptyp]. Search results were narrowed by selecting studies in humans, written in Portuguese or English, with open access, and comprising the following article types: clinical study, congress, consensus development conference, or guide- 
Table 1. Standardized mortality rates for breast cancer in Portugal, by region (2010-2015) (7)

\begin{tabular}{lccccccc} 
& North & Center & LTV & Alentejo & Algarve & Azores Islands & Madeira Islands \\
\hline All ages (deaths) & 461 & 359 & 525 & 149 & 74 & 37 & 55 \\
All ages (SMR) & 15.5 & 15.6 & 20.9 & 21.1 & 20.2 & 20.6 & 25.9 \\
<65 years (deaths) & 178 & 96 & 164 & 49 & 90 & 11 & 18 \\
$<65$ years (SMR) & 9.3 & 8.3 & 11.6 & 13.7 & 13.7 & 9.7 & 13.2
\end{tabular}

SMR: Standardized Mortality Rates; LTV: Lisbon and Tagus Valley

line. Relevant articles within the study's scope were selected. National cancer initiatives relevant for the quality of care, as well as national and international guidelines and consensus acknowledged in Europe and Portugal were further included.

\section{Epidemiological overview of breast cancer}

Breast cancer is the second most common cancer worldwide after lung cancer, and the leading cancer in women (1). With an incidence of 1.67 million in 2012, estimates indicate a rise to 1.97 in 2020 (1). Such incidence is unevenly distributed, higher in Western Europe, Australia, New Zealand, and North America, and lower in Africa and Asia. Half of new cases are reported in less developed regions $(2,3)$.

Breast cancer ranks as the fifth cause of death from cancer worldwide and the leading cause of cancer-related deaths in Europe (1). In 2012, 131.347 people died of breast cancer-related causes in Europe, with projections estimating 141.053 deaths in 2020 (1). In 2010, the national registry - North Regional Oncology Registry (RORENO) - reported 1.659 deaths (out of 6.541 diagnosis) from breast cancer in Portugal (3).

An increase in breast cancer incidence has been reported over the last years due to aging of the population and to introduction of screening programs (4). This led to an increase in disease prevalence, also partly accountable to better treatment outcomes $(1,4)$.

Approximately 5-10\% of new cases are diagnosed in advanced (locally advanced and metastatic) stages of the disease, responsible for the majority of breast cancer-related deaths (5). Metastatic breast cancer remains an incurable disease, with a median overall survival (OS) of 2-3 years (6).

In Portugal, breast cancer incidence was 6.608 per 100.000 inhabitants in 2010, according to RORENO, and 6.088 per 100.000 inhabitants in 2012 with a projection of 6.479 per 100.000 in 2020 , accord-

\section{Key Points}

- $\mathrm{H} 360$ intends to provide a comprehensive, overall picture of breast cancer management in Portugal.

- $\quad$ Setting key performance measures (KPIs) in cancer-treating institutions can leverage the quality of clinical performance.

- A multidisciplinary approach within one health structure is desirable.

- More investment in clinical (including academic) research is crucial. ing to GLOBOCAN $(1,3)$. The 2017 Portuguese Health Authority (Direção-Geral da Saúde, DGS) analysis of incidence and mortality of the most common cancers in Portugal between 2011 and 2015 reported more than 1.600 deaths every year attributable to female breast cancer, with a maximum of 1.752 deaths in 2012 (7). However, there is a regional and age asymmetry in these figures (Table 1) (7).

Although breast cancer incidence is steadily increasing worldwide, a drop or stabilization on incidence rates, particularly in white postmenopausal women, has been reported in developed countries at the beginning of the $21^{\text {st }}$ century (4). However, the number of new diagnoses in women under the age of 45 is still increasing $(1,4)$. In Europe, up to a quarter of breast cancer cases occur before the age of 50 , and less than $5 \%$ before the age of 35 (4).

A similar trend is observed in Portugal, with a global breast cancer incidence of 62.5 per 100.000 cancer cases and an incidence peak between the ages of 65-69 (3). The disease incidence markedly increases until the age of 45, steadily increases until the age of 69, and slightly decreases afterwards (3).

\section{Breast cancer outcomes within the Portuguese healthcare structure}

Several studies have sought to investigate the costs of breast cancer care and established guidelines for quality assurance in breast cancer screening and diagnosis (8).

Studies are disparate regarding cancer outcomes and health care expenditure, with some showing that a higher healthcare expenditure may not always translate into improved outcomes and others showing otherwise $(9,10)$.

Analysis of the correlation between variables associated with the healthcare system and cancer outcomes might be relevant. Studies have been published comparing differences in cancer outcomes in developed countries with comparable healthcare systems $(9,11,12)$. Factors that have been identified as potentially negatively impacting cancer outcomes include the centralization of services, patient lists per general practitioner, patients having unrestrained access to different primary care physicians, and access time to secondary care $(9,11)$. However, a causal correlation could not be established for any of these factors.

In Portugal, multicenter studies have investigated breast cancer outcomes, including effectiveness of adjuvant ovarian function suppression in premenopausal women with early breast cancer, use of different types of adjuvant chemotherapy in patients with stage I breast cancer, and treatment adoption and relative effectiveness of aromatase inhibitors (AIs) compared to tamoxifen in early breast cancer $(13,14)$. Analysis of results from these multi-institutional studies - made possible by data assembled in the Regional Oncology Registries (RORs) - allow to 
Table 2. Treatment and access and patients flow performance indicators for breast cancer [adapted from Khare SR et al. 2016] (16)

\section{Indicator Description}

Treatment

1

Percentage of patients with early stage breast cancer (stage I or II) and clinically negative axillary nodes who receive sentinel node biopsy

Complete synoptic pathology report according to the Canadian Association of Pathologists or Rossy Cancer Network guidelines

3 Percentage of patients with involvement of axillary lymph nodes (1-3 nodes or more) who received adjuvant radiation

4 Percentage of patients with estrogen receptor-negative invasive carcinoma (tumor $>1 \mathrm{~cm}$ or node-positive) who received adjuvant chemotherapy within 8 weeks of surgical resection

5

Percentage of patients with inflammatory breast cancer or locally advanced nonresectable estrogen receptor-negative carcinoma who received neoadjuvant chemotherapy

6 Percentage of patients with stage III breast cancer who underwent baseline staging, including bone scan, liver ultrasonography, and chest radiography

$7 \quad$ Percentage of patients who received systemic-relapse post-adjuvant therapy within 5 years of diagnosis

$8 \quad$ Percentage of patients with primary operable breast cancer who developed first recurrence to ipsilateral breast or skin or chest wall (or both) within 5 years after mastectomy or breast-conserving surgery

9

Percentage of biopsies performed at first site of metastasis (stage IV patients)

10

Percentage of patients receiving chemotherapy with grade 4 toxicity

\section{Access and patient flow}

11

12

13

14

15

16

17

18

19
Time from abnormal mammogram to diagnostic biopsy

Time from diagnostic biopsy to initial breast cancer surgery

Percentage of breast cancer patients treated on a clinical trial

Percentage of breast cancer patients offered referral to genetics for evaluation and counselling

Percentage of breast cancer patients presented to the multidisciplinary tumor conference (tumor broad) at any time after diagnosis

Wait time for adjuvant radiation therapy from the final pathology report

Wait time for systemic therapy from the final pathology report

Wait time for first line chemotherapy for metastatic disease, from medical oncology visit that decides on chemotherapy

Wait time for computed tomography or magnetic resonance imaging from doctor's requisition derive clinical and financial implications, as modifications to clinical practice and financial resource allocation.

The fourth edition of the European guidelines for quality assurance in breast cancer screening and diagnosis stresses the importance of breast cancer screening, but also of providing highly effective diagnostic services and developing specialized breast units (8). Nevertheless, it has been shown that early breast cancer detection and diagnosis do not always significantly impact disease-associated mortality (8).

Additionally, it is acknowledged that implementation of clinical practice guidelines in cancer care improves patient outcomes. The European Society of Breast Cancer Specialists (EUSOMA) provided a voluntary certification process for breast centers that ensure multidisciplinary care and minimum standards of care (15).

Setting performance measures - known as Key Performance Indicators (KPIs) - in cancer is a mechanism of quality monitoring and mea- surement with improvement purposes (Table 2) (16). KPIs allow a meaningful comparison between cancer centers and the identification of areas for improvement, including in the patient care pathway. It should be noted that differences in disease stage at the time of presentation may reflect different patterns of access to diagnosis and that a KPI-based assessment will provide insights into significant disparities between different hospitals, always taking into account the demographic differences in breast cancer incidence and mortality that exist in Portugal. KPIs are increasingly becoming a formal requirement in healthcare delivery in most institutions around the world.

Engaging national clinicians and their institutions to set KPIs as a key element in cancer care has the potential to leverage the quality of clinical performance.

Additionally, integration of different disciplines - General Practice, Imaging, Pathology, Surgery, Radiotherapy, Medical Oncology, spe- 
cialized Nursing, Public Health, Pharmacy, Economy, Patient Advocacy, and Hospital Administration - within one structure is desirable as the foundation for a true patient-centered approach.

A systematic analysis using KPIs as a tool for assessing quality of care remains an unmet need in Portugal.

\section{Clinical research}

Investment in clinical research in Portugal is lower compared with most other European countries that are part of the European Union (EU). This is true both for academic and industry-sponsored trials (17). Overall, a low number of clinical, mostly Phase III trials are taking place in Portuguese Centers, along with an even lower number of registry and academic studies. In the academic setting, investigation of the BRCA gene in the Portuguese breast cancer population is an example of research developed in the country over the last years. More recently, multicenter studies have investigated breast cancer outcomes in the Portuguese patient population $(11,13,14)$.

\section{Clinical practice guidelines}

The most widely used guidelines in breast cancer management are the European Society for Medical Oncology (ESMO) Breast Cancer Guidelines and the National Comprehensive Cancer Network (NCCN) Guidelines in Breast Cancer, with remarkable differences in levels of evidence and grades of recommendation $(4,18)$.

In Portugal, breast cancer guidelines issued by the Portuguese Health Authority DGS and by the Portuguese Society of Breast Cancer (Sociedade Portuguesa de Senologia, SPS) are available to guide clinical decisions $(4,19)$. DGS guidelines are largely based on ESMO guidelines but lack comprehensive information on several aspects of breast cancer management. The SPS guidelines are more detailed and regularly updated (every two years).

\section{Breast cancer risk factors}

Recognized risk factors for breast cancer are those intrinsic to the subject - female gender, older age, early menarche, late menopause, age at first pregnancy, and family history of breast cancer at young age and those associated with previous treatments - including hormonal therapy substitution and radiotherapy (RT) of the thoracic wall (4). Other acknowledged risk factors are presence or history of benign disease of the breast, high-density breast, and genetic factors, particularly BRCA1/2 gene mutations $(20,21)$. Lifestyle and dietary factors also play a role, with obesity and inactivity associated with a higher risk in postmenopausal women and dose-dependent alcohol consumption (and possibly also tobacco) associated with a higher risk in both preand post-menopausal women (4).

\section{Breast cancer screening}

Breast cancer screening is performed in women without signs or symptoms of the disease, for an earlier-as-possible detection.

Many European countries established national or regional populationbased mammography screening programs to detect breast cancer at a preclinical stage. The European guidelines for quality assurance in breast cancer screening and diagnosis recommend implementation and monitoring of performance parameters and indicators in every
According to ESMO guidelines, mammography screening every two years has the greatest mortality reduction benefit in the 50-69 age group, and Portugal complies to this recommendation $(4,7,22)$. Following the same guidelines, annual magnetic resonance imaging (MRI) concomitantly or alternating with mammography every six months is recommended in the country for patients in high risk for breast cancer (22).

\section{Breast cancer diagnosis}

At least $60 \%$ of breast cancer patients present with a breast lump which may or may not be painful, fixed or demarcated from the surrounding tissue (4). Unlike screening imaging, which is used to detect cancer in asymptomatic women, diagnostic evaluation is used to characterize a clinical finding or a possible abnormality during screening.

Breast cancer diagnosis is based on clinical examination combined with imaging and confirmed with pathologic assessment. Clinical examination includes assessment of general health status and of the primary tumor, regional lymph nodes, and possible distant metastases. Imaging includes bilateral mammography and ultrasound of the breast and regional lymph nodes. In accordance with ESMO guidelines, breast MRI should be considered only in cases of familiar breast cancer associated with BRCA mutations, breast implants, lobular cancers, suspicion of multifocality/multicentricity, large discrepancies between conventional imaging and clinical examination, or in the context of neoadjuvant therapy (22).

Pathological diagnosis should be based on a core needle biopsy. Analysis of tissue sample should allow detection of invasive tumor growth and identification of histological type, tumor hormone (estrogen [ER] and progesterone $[\mathrm{PR}]$ ) receptor (HR) status, human growth factor receptor 2 (HER2) status, and ki-67 expression.

\section{Breast cancer staging}

Every patient with breast cancer should be assigned a clinical and a pathological stage of disease, according to the TNM (primary tumor $[\mathrm{T}]$, regional lymph nodes $[\mathrm{N}]$, distant metastasis $[\mathrm{M}]$ ) system of the American Joint Committee for Cancer (AJCC) (23). The most recent (eight) edition highlights that ensuing advances in clinical and laboratory science and translational research seriously challenge the relevance of the previously used purely anatomic TNM staging for breast cancer. Therefore, while anatomic TNM classification remained the basis for the eighth edition staging groups, tumor grade, hormone receptor status, and HER2 status have been considered important additional determinants of outcome, and have now been incorporated into parallel prognostic stage groups that recognize the intrinsic tumor biology (23).

\section{Breast cancer treatment}

Breast cancer treatment should be guided by several factors, including tumor burden, location, and biology, patient's general health status and comorbidities and, very importantly, patient preferences.

The treatment strategy must always comprise a multidisciplinary approach incorporating specific therapies (surgery, radiation therapy, medical therapy, and others) with imaging and pathology assessment (including molecular profile, if needed). In the era of personalized medicine, integration of these therapeutic tools is mandatory for an optimal medical practice. 


\section{Early breast cancer}

Curative resection of the tumor and involved lymph nodes remains the cornerstone of breast cancer treatment. In Western Europe, 60-80\% of newly diagnosed cancers are submitted to breast conserving surgery (BCS) followed by RT.

Guidelines agree that all patients should be considered for postoperative whole breast RT following BCS.

Adjuvant systemic treatment should be considered after surgery according to relapse risk and tumor characteristics. It is recommended for most triple negative (TN), HER2-positive, and high-risk luminal HER2-negative tumors.

Assessing tumor biology features - like tumor intrinsic subtype - rather than relying solely on standard criteria has the potential to improve response to systemic therapies. Low-risk luminal A tumors can often be treated with endocrine therapies (ETs) alone. Luminal B tumors usually require both chemotherapy (CT) and ET and HER2-positive tumors rely on adjuvant CT plus anti-HER2 therapy (22). Moreover, gene expression profiles may be used for additional prognostication and predictive information regarding the potential utility of adjuvant CT (22).

For HR- and HER2-positive disease, ESMO guidelines recommend CT plus anti-HER2 therapy for all patients (except in selected cases with very low risk, such as T1aN0 tumors). ESMO and NCCN guidelines currently recommend adjuvant ado-trastuzumab emtansine instead of trastuzumab for HER2-positive cases with residual disease after neoadjuvant therapy and surgery (24). In the adjuvant setting, the same guidelines consider dual HER2 blockade with trastuzumab and pertuzumab for 1 year (for high-risk patients with $\mathrm{N}$-positive or ER-negative disease) or neratinib (for selected high-risk patients not previously treated with dual HER2 blockade) $(22,25,26)$.

ET is indicated for all patients with detectable HR expression (defined as $\geq 1 \%$ of invasive cells). Agent choice is primarily determined by patient menopausal status. CT is generally selected for high-risk or luminal A tumors with extensive local disease, also considering patient's genetic profile (22).

TN tumors benefit from adjuvant CT, with the eventual exception of low-risk histological subtypes, such as secretory juvenile, apocrine, or adenoid cystic carcinomas.

Protocols for this tumor stage are well described at ESMO, NCCN, American Society of Clinical Oncology (ASCO), and Saint Gallen guidelines $(18,22,27,28)$. In Portugal, treatment decisions are evidence-based, according to what is stated in the referred guidelines. Recently, Arlindo et al. reported variations in the type of adjuvant chemotherapy received by stage I breast cancer patients in a multiinstitutional Portuguese cohort (29). This study showed that most patients receive non-intensive regimens (such as doxorubicin plus cyclophosphamide) and that taxane-based non-intensive regimens (such as docetaxel plus cyclophosphamide) were infrequently used. It also reported striking institutional variations in chemotherapy use (ranging from 0 to $43.4 \%$ ) (29).

\section{Advanced breast cancer}

Advanced breast cancer ( $\mathrm{ABC}$ ) includes both locally advanced breast cancer $(\mathrm{LABC})$ and metastatic breast cancer $(\mathrm{MBC})$ and the disease management encompasses both treatment and supportive care.

\section{Locally advanced breast cancer (inoperable and non-metastatic)}

Systemic treatment should be the initial choice for LABC, with a combined treatment modality (systemic therapy, RT, and surgery) indicated in most cases. CT is the recommended option for most patients, with anthracycline- and taxane-based CT as standard regimens.

For HER2-positive breast cancer, concurrent anti-HER2 therapy plus $\mathrm{CT}$ is recommended after evidence showing an increase in the rate of pathologic complete response (pCR) $(30,31)$.

Surgery is an option for some patients following primary CT. Mastectomy with axillary dissection can be considered in most cases. For patients with axillary low burden of disease at presentation with complete response after systemic treatment, sentinel lymph node biopsy can be an option (6). As there is a significant risk of recurrence, adjuvant RT is indicated after surgery for most patients.

Adjuvant ET and up to one year of trastuzumab should be completed following surgery in HR- and HER2-positive patients, respectively. In both cases, concurrent administration of adjuvant RT is possible.

\section{Metastatic breast cancer}

In this setting, although treatable the disease is virtually incurable and treatment intent is palliative. Median OS for MBC is 3 years and 5 -year survival is approximately $25 \%(32,33)$.

Systemic therapy is the most frequent option and decisions are taken according to HR and HER2 expression status, tumor burden, response to previous therapies and associated toxicities, disease-free interval (DFI, in case of breast cancer recurrence), need for rapid disease control (e.g. visceral crisis), and patient characteristics, as comorbidities, performance status, age, menopausal status, psychological factors, and socio-economic situation.

In this setting, the main clinical endpoints are improvement of OS and progression-free survival (PFS), symptomatic control, metastatic remission and quality of life (QoL).

Both NCCN and the $4^{\text {th }}$ ESO-ESMO International Consensus Guidelines for Advanced Breast Cancer (ABC4) are widely adopted for MBC treatment and used in Portugal $(6,18)$.

Radiological assessment plays an important role in treatment of bone and brain metastases. Metastases-directed surgery is also performed in some patients, including those with bone lesions with impeding fracture risk or spinal cord compression and in selected patients with operable lung or liver metastases.

\section{Quality of life and social integration - Where do we stand?}

Breast cancer is the most prevalent tumor type in women globally (34). The number of women living with the disease increases every year, including those with metastatic and recurrent disease (35). Since breast cancer has a considerable impact on women's QoL from the moment of diagnosis, this is an increasingly relevant issue for breast cancer survivors (36).

QoL is increasingly recognized by health care professionals as a treatment goal on its own and has been incorporated in clinical guidelines issued by the main organisations involved in cancer care worldwide. 
ESMO and NCCN guidelines provide recommendations on the subject, with NCCN yielding important indications, although predominantly focused on supportive and palliative care (6). ESMO also recently issued the ESMO Magnitude of Clinical Benefit Scale, providing a validated tool to assess the magnitude of clinical benefit from new cancer therapies taking into account multiple variables, including QoL (37). ABC4 specifically focuses QoL as a critical parameter for an optimal disease management (6).

The ability to perform daily activities, as well as functioning levels and patient satisfaction are key issues when addressing QoL in breast cancer survivors (36).

Validated instruments for measuring QoL are in place, which allow for comparisons between different population and country outcomes and provide valuable tools for research, clinical practice, and policy making (38). Most used cancer-specific (including breast cancer-specific) instruments include the European Organization for Research and Treatment of Cancer-Breast Module (EORTC QLQ-BR23) and the Functional Assessment of Cancer Therapy-Breast (FACT-B) (39).

The population of breast cancer survivors has disparate health requirements due to heterogeneity of sociodemographic characteristics, preexisting comorbidities, tumor stage at diagnosis, tumor biology characteristics, and experienced treatment modalities.

According to patients' perceptions, healthcare professionals do not provide sufficient information regarding disease progression, coping skills, and patient education resources, making them seek information and support from various organizations (40). Furthermore, when discussing treatment options with their patients, physicians should inform them on QoL differences associated with different options (41).

Because MBC has a median survival of $2-3$ years after diagnosis, treatment is focused on disease control and QoL (42). However, and despite efforts, QoL for these patients has not improved over the last decade $(5,32)$.

Challenges for men with MBC are even bigger, since they are a generally neglected subpopulation (43).

The Global MBC Vision 2025 Call-to-Action program has been developed and is currently in progress to address the unmet needs faced by MBC patients and help define optimal care practices for this vulnerable group (44).

Supportive care should be an integral part of the treatment plan offered to MBC patients. ABC4 strongly recommends access to palliative care early after $\mathrm{MBC}$ diagnosis, emphasizing that patient preferences at the end of life should not be neglected but instead discussed in a timely manner (6). Also NCCN guidelines consider palliative care a key aspect of metastatic and recurrent disease management (18).

During the first year after a breast cancer diagnosis, women experience significant psychological distress, including feelings of shock, emotional numbness, depression, and anxiety $(44,45)$. Many patients also experience cognitive alterations induced by cancer and cancer treatments (onco-brain). Additionally, the burden of systemic adjuvant treatment in breast cancer is associated with weight gain, infertility, and early menopause (46).

Fertility preservation is an important aspect of cancer care, with sev- tion, oocyte cryopreservation, ovarian tissue cryopreservation, and transplantation (47). In 2016, the Portuguese Society of Oncology issued oncofertility recommendations, to be implemented in Portugal, providing information on preservation of the reproductive potential in adult cancer patients based on available evidence (47). These have been implemented in specialized oncofertility centers nationwide.

Sexual function and satisfaction can also be affected by the disease and cause great personal and interpersonal suffering. Choice of the type of surgery is a key aspect for women to preserve their sexual satisfaction and adequate body image (48).

Cancer patients have a higher risk of second malignancies and subsequent tumors compared with the general population, partly due to genetic predisposition but also to toxicity of therapeutic modalities (49).

Conventional chemotherapies and some of the most recent anticancer signaling inhibitors carry a substantial risk of cardiovascular side effects that include cardiac dysfunction and heart failure, arterial hypertension, vasospastic and thromboembolic ischemia, dysrhythmia, and CT prolongation (50).

Patients desire a holistic, individualized, compassionate, and culturally sensitive dialogue with their healthcare providers, within a shared decision making process (40).

In Portugal, there is an absence of long survivor support groups, with only a few closed support groups for MBC patients and some hospitalbased groups to assist patients during their treatments. 'Fundo iMMLaço' contributes with research grants but is not enough to fulfill this unmet need.

Recently, the Portuguese National Authority of Medicines and Health Products (INFARMED) launched "Projeto Incluir" (Project "To Include") as a vehicle for a better interaction between patients and their community representatives (50). The project aims to expand the contribution of patient advocacy groups in assessing health technologies, drug stock-outs, adverse reaction notification, and counterfeit medicine identification, among others.

ABC4 foresees that patients should be able to have an active working life if they desire or need. But for that to be possible, patients should be allowed working schedule flexibility, in order to attend hospital appointments and treatments whenever necessary. This remains an unmet need, highlighting the need for changes in societal structure and behavior. The Global Alliance for breast cancer is strongly committed towards this purpose (50).

Overall, it is key to establish an effective multidimensional survivorship program, in order to develop management guidelines specific for breast cancer survivors and properly train clinicians on the best way to discuss treatment options, prognosis, and end-of-life care with their patients.

\section{Conclusion}

Breast cancer is a significant health challenge for patients, their families, and society in general. A multidimensional approach that goes beyond the clinical perspective may provide new insights and directions to study the impact of this still highly prevalent malignancy.

The undertaking of providing a comprehensive picture of the disease, in a 360-degree appraisal, although intuitively desirable, is not simple. Set to 
this task, the current project proposes to analyze real-world data from a 360-degree perspective, i.e., from the medical interpretation of evidencebased data to the patient perspective on the quality and effectiveness of services and medical care provided, also including the perspective of administrators and decision-makers. Using such comprehensive approach, the full impact of breast cancer on patients and society can be analyzed.

In Europe, although the Primary Care setting is key for prevention, early detection of breast cancer, disease diagnosis, treatment, and follow-up occur mainly at the hospital setting. In Portugal, the National Health Service (NHS) is provided by public institutions, but the role of private hospitals is increasing and expanding and currently accounts for a significant proportion of breast cancer care in major cities. This first initiative - the 360 Health Analysis (H360) - consists of a multidimensional analysis of breast cancer in 10 , mostly public, Portuguese hospitals with different socio-geographic characteristics, all of which are part of the NHS.

With this approach, the authors believe they will be able to provide very relevant clinical and non-clinical data, particularly useful for stakeholders involved in breast cancer management, and to widen the critical perspective on breast cancer research and management for future $\mathrm{H} 360$ studies. Ultimately, this initiative aims to assist clinical and management decisions in breast cancer towards a more patientcentered approach.

Peer-review: Externally peer-reviewed.

Author Contributions: Concept - L.C., R.B.L., F.P.; Design - L.C., R.B.L.; Supervision - L.C., M.R.D.; Resources - L.C., M.R.D., S.C., I.B.R., P.M.S.; Materials - M.R.D., S.C., I.B.R., P.M.S.; Data Collection and/or Processing - M.R.D., S.C., I.B.R., P.M.S.; Analysis and/or Interpretation - M.R.D., S.C., I.B.R., P.M.S.; Literature Search - S.C., I.B.R., M.R.D., P.M.S.; Writing Manuscript - S.C., I.B.R., M.R.D., J.C.S., P.M.S.; Critical Review - L.C., S.C., I.B.R., M.R.D., J.C.S., R.B.L., F.P., P.M.S.

Conflict of Interest: The authors have no conflicts of interest to declare.

Financial Disclosure: H360 project received an unrestricted grant from Pfizer.

\section{References}

1. Ferlay J, Soerjomataram I, Dikshit R, Eser S, Mathers C, Rebelo M, et al. Cancer incidence and mortality worldwide: Sources, methods and major patterns in GLOBOCAN 2012. Int J Cancer 2015; 136: E359-E386. (PMID: 25220842) [CrossRef]

2. Ferlay J, Steliarova-Foucher E, Lortet-Tieulent J, Rosso S, Coebergh JW, Comber $\mathrm{H}$, et al. Cancer incidence and mortality patterns in Europe: estimates for 40 countries in 2012. Eur J Cancer 2013; 49: 1374-1403. (PMID: 23485231) [CrossRef]

3. RORENO. Registo Oncológico Nacional 2010. Instituto Português de Oncologia do Porto Francisco Gentil - EPE. ed Porto. 2016.

4. Senkus E, Kyriakides S, Ohno S, Penault-Llorca F, Poortmans P, Rutgers E, et al. Primary breast cancer: ESMO Clinical Practice Guidelines for diagnosis, treatment and follow-up. Ann Oncol 2015; 26(Suppl 5): v8-30. (PMID: 26314782) [CrossRef]

5. Cardoso F, Beishon M, Cardoso MJ, Corneliussen-James D, Sabelko K, Gralow J, et al. Global Analysis of Advanced/Metastatic Breast Cancer: Decade Report (2005-2015). Breast 2018; 39: 131-138. (PMID: 29679849) [CrossRef]

6. Cardoso F, Senkus E, Costa A, Papadopoulos E, Aapro M, Andre F, et al. 4th ESO-ESMO International Consensus Guidelines for Advanced
Breast Cancer (ABC 4). Ann Oncol 2018; 29: 1634-1657. (PMID: 30032243) [CrossRef]

7. Miranda N GB, Andrade C, Santos G. Programa Nacional Para as Doenças Oncológicas da Direção Geral de Saúde. 2017.

8. Perry N, Broeders M, de Wolf C, Tornberg S, Holland R, von Karsa L. European guidelines for quality assurance in breast cancer screening and diagnosis. Fourth edition - summary document. Ann Oncol 2008; 19: 614-622. (PMID: 18024988) [CrossRef]

9. Sullivan R, Peppercorn J, Sikora K, Zalcberg J, Meropol NJ, Amir E, et al. Delivering affordable cancer care in high-income countries. Lancet Oncol 2011; 12: 933-980. (PMID: 21958503)

10. Mitchell E, Macdonald S, Campbell NC, Weller D, Macleod U. Influences on pre-hospital delay in the diagnosis of colorectal cancer: a systematic review. Br J Cancer 2008; 98: 60-70. (PMID: 18059401) [CrossRef]

11. Brown S, Castelli M, Hunter DJ, Erskine J, Vedsted P, Foot C, et al. How might healthcare systems influence speed of cancer diagnosis: a narrative review. Sociol Health Illn 2014; 116: 56-63. (PMID: 29446117) [CrossRef]

12. De Angelis R, Sant M, Coleman MP, Francisci S, Baili P, Pierannunzio D, et al. Cancer survival in Europe 1999-2007 by country and age: results of EUROCARE-5-a population-based study. Lancet Oncol 2014; 15: 2334. (PMID: 24314615) [CrossRef]

13. Ferreira AR, Ribeiro J, Mayer A, Brito M, Miranda A, Fernandes JP, et al. 181PUse and effectiveness of adjuvant ovarian function suppression (OFS) in premenopausal women with early breast cancer. Ann Oncol 2017; 28(Suppl 5):mdx362.031-mdx362.031. [CrossRef]

14. Ferreira AR, Palha A, Correia L, Filipe P, Rodrigues V, Miranda A, et al. Treatment adoption and relative effectiveness of aromatase inhibitors compared to tamoxifen in early breast cancer: A multi-institutional observational study. Breast 2018; 37: 107-113. (PMID: 29131988) [CrossRef]

15. van Dam PA, Tomatis M, Marotti L, Heil J, Mansel RE, Rosselli Del Turco M, et al. Time trends (2006-2015) of quality indicators in EUSOMA-certified breast centres. Eur J Cancer 2017; 85: 15-22. (PMID: 28881247) [CrossRef]

16. Khare SR, Batist G, Bartlett G. Identification of performance indicators across a network of clinical cancer programs. Crr Oncol 2016; 23: 81-90. (PMID: 27122972) [CrossRef]

17. EPFIA annual report, 2016. Available from: https://www.efpia.eu/media/219734/efpia_annual-report_2017_interactive.pdf (accessed 28 July 2019).

18. NCCN Clinical Practice Guidelines in Oncology: Breast Cancer. Version 1.2019

19. Recomendaçōes Nacionais para o diagnóstico e tratamento do cancro da mama. https://www.dgs.pt/documentos-e-publicacoes/recomendacoesnacionais-para-diagnostico-e-tratamento-do-cancro-da-mama.aspx (accessed 19 November 2019).

20. Miki Y, Swensen J, Shattuck-Eidens D, Futreal PA, Harshman K, Tavtigian $\mathrm{S}$, et al. A strong candidate for the breast and ovarian cancer susceptibility gene BRCA1. Science 1994; 266: 66-71. (PMID: 7545954) [CrossRef]

21. Wooster R, Bignell G, Lancaster J, Swift S, Seal S, Mangion J, et al. Identification of the breast cancer susceptibility gene BRCA2. Nature 1995; 378: 789-792. (PMID: 8524414) [CrossRef]

22. Cardoso F, Kyriakides S, Ohno S, Penault-Llorca F, Poortmans P, Rubio IT, et al. Early breast cancer: ESMO Clinical Practice Guidelines for diagnosis, treatment and follow-up. Ann Oncol 2019; 30: 1194-1220. (PMID: 31161190) [CrossRef]

23. UICC. TNM Classification of Malignant Tumours 8th edition. 2016.

24. von Minckwitz G, Huang CS, Mano MS, Loibl S, Mamounas EP, Untch $\mathrm{M}$, et al. Trastuzumab Emtansine for Residual Invasive HER2-Positive Breast Cancer. N Engl J Med 2019; 380: 617-628. (PMID: 30516102) [CrossRef]

25. von Minckwitz G, Procter M, de Azambuja E, Zardavas D, Benyunes M, Viale G, et al. Adjuvant Pertuzumab and Trastuzumab in Early HER2Positive Breast Cancer. N Engl J Med 2017; 377: 122-131. (PMID: 28581356) [CrossRef] 
26. Martin M, Holmes FA, Ejlertsen B, Delaloge S, Moy B, Iwata H, et al. Neratinib after trastuzumab-based adjuvant therapy in HER2-positive breast cancer (ExteNET): 5-year analysis of a randomised, double-blind, placebo-controlled, phase 3 trial. Lancet Oncol 2017; 18: 1688-1700. (PMID: 28581356)

27. Curigliano G, Burstein HJ, Winer EP, Gnant M, Dubsky P, Loibl S, et al. De-escalating and escalating treatments for early-stage breast cancer: the St. Gallen International Expert Consensus Conference on the Primary Therapy of Early Breast Cancer 2017. Ann Oncol 2017; 28: 1700-1712. (PMID: 28838210)

28. Burstein HJ, Lacchetti C, Anderson H, Buchholz TA, Davidson NE, Gelmon KE, et al. Adjuvant Endocrine Therapy for Women With Hormone Receptor-Positive Breast Cancer: American Society of Clinical Oncology Clinical Practice Guideline Update on Ovarian Suppression. J Clin Oncol 2016; 34: 1689-1701. (PMID: 26884586) [CrossRef]

29. Ferreira AR, Palha A, Correia L, Filipe P, Rodrigues V, Costa L, et al. Variation in type of adjuvant chemotherapy received among patients with stage I breast cancer: A multi-institutional Portuguese cohort study. Breast 2016; 29: 68-73. (PMID: 27468923) [CrossRef]

30. Liedtke C, Mazouni C, Hess KR, Andre F, Tordai A, Mejia JA, et al. Response to neoadjuvant therapy and long-term survival in patients with triple-negative breast cancer. J Clin Oncol 2008; 26: 1275-1281. (PMID: 18250347) [CrossRef]

31. Cortazar P, Zhang L, Untch M, Mehta K, Costantino JP, Wolmark N, et al. Pathological complete response and long-term clinical benefit in breast cancer: the CTNeoBC pooled analysis. Lancet 2014; 384: $164-$ 172. (PMID: 24529560) [CrossRef]

32. Cardoso F, Spence D, Mertz S, Corneliussen-James D, Sabelko K, Gralow $\mathrm{J}$, et al. Global analysis of advanced/metastatic breast cancer: Decade report (2005-2015). Breast 2018; 39: 131-138. (PMID: 29679849) [CrossRef]

33. SEER Cancer Statistics Review, 1975-2013. Bethesda, MD: National Cancer Institute. Available from: https://seer.cancer.gov/archive/ csr/1975_2013/ (accessed 28 July 2019).

34. Jemal A, Bray F, Center MM, Ferlay J, Ward E, Forman D. Global cancer statistics. CA Cancer J Clin 2011; 61: 69-90. (PMID:21296855) [CrossRef]

35. Mariotto AB, Etzioni R, Hurlbert M, Penberthy L, Mayer M. Estimation of the Number of Women Living with Metastatic Breast Cancer in the United States. Cancer Epidemiol Biomarkers Prev 2017; 26: 809-15. (PMID: 28522448) [CrossRef]

36. Costa WA, Eleuterio J, Jr., Giraldo PC, Goncalves AK. Quality of life in breast cancer survivors. Rev Assoc Med Bras (1992) 2017; 63: 583-589. (PMID:28977083) [CrossRef]
37. Cherny NI, Dafni U, Bogaerts J, Latino NJ, Pentheroudakis G, Douillard JY, et al. ESMO-Magnitude of Clinical Benefit Scale version 1.1. Ann Oncol 2017; 28: 2340-2366. (PMID: 28945867) [CrossRef]

38. WHO, WHOQOL: Measuring Quality of Life. 2014. Available from: http://www.who.int/healthinfo/survey/whoqol-qualityoflife/en/ (accessed 28 July 2019).

39. Chopra I, Kamal KM. A systematic review of quality of life instruments in long-term breast cancer survivors. Health Qual Life Outcomes 2012; 10: 14. (PMID: 22289425) [CrossRef]

40. Cardoso F, Beishon M, Carodos M, Corneliussen-James D, Gralow J, Mertz S, et al. Breast Cancer Center Survey:Cancer center management, support, and perception of $\mathrm{mBC}$ patient needs across 582 healthcare professionals. 2018. Available from: http://docplayer.net/51370811-Breastcancer-center-survey-cancer-center-management-support-and-perception-of-mbc-patient-needs-across-582-healthcare-professionals.html (accessed 28 July 2019).

41. Tsai HY, Kuo RN, Chung KP. Quality of life of breast cancer survivors following breast-conserving therapy versus mastectomy: a multicenter study in Taiwan. Jpn J Clin Oncol 2017; 47: 909-918. (PMID: 28981734) [CrossRef]

42. Metastatic Breast Cancer Network. 13 facts about metastatic breast cancer. 2015. Available from: http://www.crcdinc.org/whats-new/2017/7/10/13facts-about-metastatic-breast-cancer-stage-iv (accessed 28 July 2019).

43. Di Lascio S, Pagani O. Is it time to address survivorship in advanced breast cancer? A review article. Breast 2017; 31: 167-172. (PMID: 27871024) [CrossRef]

44. Global mBC Vision 2025 Call-to-Action. Available from: https:// www.breastcancervision.com/sites/default /files/Linear\%20mBC\%20 CTA\%20Layout_Final\%202.pdf (accessed 19 November 2019).

45. Henry BJ. Quality of Life and Resilience: Exploring a Fly Fishing Intervention for Breast Cancer Survivors. Clin J Oncol Nurs 2017; 21: E9E14. (PMID: 28107325) [CrossRef]

46. O'Donoghue C, Quinn GP, Lee MC. Fertility Preservation in Breast Cancer. South Med J 2017; 110: 621-626. (PMID: 28973701) [CrossRef]

47. Santos AT, Sousa G, Teixeira A, Cardoso P, Melo C, Teixeira A, et al. Recomedaçóes para a preservaçáo do potencial reprodutivo no doente oncológico. Revista Portuguesa de Oncologia 2016; 2: 5-24.

48. Cardoso F. 100 Perguntas Chave no Cancro da Mama 2017, 2nd edition, Available from: https://www.sponcologia.pt/fotos/editor2/publicacoes/2_100_mama.pdf (accessed 28 July 2019). Permayer Portugal. 2015.

49. Suter TM, Ewer MS. Cancer drugs and the heart: importance and management. Eur Heart J 2013; 34: 1102-1111. (PMID: 22789916) [CrossRef]

50. Projeto Incluir. Available from: http://www.infarmed.pt/web/infarmed/ cidadaos/doentes-e-associacoes-de-doentes (accessed 28 July 2019). 